"victims" of valvular disease considered war-worthy by some disciples of the cult in question.

I may refer, in conclusion, to the perplexities of your correspondent, Captain Adolphe Abrahams, whose letter appeared in THE LANCET of July 29th, induced by a study of Captain John Parkinson's paper in your issue of July 22nd, the carefully collected and well-weighed data in which render it valuable. His suggestion of an objectively flawless but essentially inadequate heart is quite in accordance with probability. Some years ago I contributed an article to THE LANCET ${ }^{3}$ on Cardiac Inadequacy, borrowing the term from an expression used by the late Sir Andrew Clark in discussing " renal inadequacy." In the paper referred to I examined the question of cardiac inadequacy rather fully. That there is a native difference in organic adequacy will scarcely be disputed, and I agree with Captain Parkinson that only a moiety of the more or less rapid and easily accelerable hearts met with in so-called "soldier's heart" are referable to hyperthyroidism. Sir James Barr's contention that cases of hyperthyroidism without pronounced enlargement of the gland are overlooked is, however, probably correct.

That defective endocrinic tone plays a part in these cases is probable, and is shown by the lack of sustained energy in cardiac action. This loss of tone appears to me to be of neural origin, and the determination of what $I$ have termed the cardio-pulmonary reflex is, I believe, a valuable index to the power of adaptation shown by the heart under exertion. An easily elicited retardation of the heart while unaccelerated, on deep respiration and a rapid return to the normal rate on the cessation of exertion, I have been taught by experience to regard as indicative of that control which denotes good cardio-vascular tone. I therefore find myself quite in accord with Captain Abrahams in ascribing importance to undue prolongation of acceleration after a given work test, and have myself employed it as such and have advised others to do so also. On the other hand, a native cardiac inadequacy without any evidence of organic or persistent disease may quite validly exclude a man from military service.

There can also be little doubt, as Captain Abrahams suggests, and it has before been pointed out, that there is a considerable psychical element in many cases of so-called "soldier's heart." The conditions of modern war are even more calculated to induce the neurasthenic state and bring such tendencies into activity than the conditions of previous wars. The frequent night attacks and high explosives, denoting as they do banished sleep and excessive stimulation, are well calculated to produce shock and disorder, especially, although by no means exclusively, in more highlystrung individuals. The cord tends to vibrate long after it has been struck, and to emit frequently a music far from exhilarating. For this reason the aggregation of neurasthenic cardiopaths in a special Cordarium, such as that which has recently been established at Hampstead, has always appeared to me to be wrong in principle. Such cases can be as well investigated and, I believe, more successfully treated outside an emphasised cardiopathic atmosphere.

I am, Sir, yours faithfully, ATIEXANDER MORISON.

Upper Berkeley-street, W., July 29th, 1916.

\section{THE SHOCKLESS OPERATION.}

\section{To the Editor of THE LANCET.}

SIR,-I was much interested to read Dr. Manson Fergusson's letter in your issue of July 15th, in answer to my article on this subject. I notice that Dr. Fergusson prefers local anæsthesia with the patient fully conscious to the method advocated in my paper. While this may be an advantage when operating upon hardy Scotch patients, and when a skilled anxsthetist is not easily obtainable, it is not generally speaking, I think, as good a method as that in which the patient is kept unconscious. Very many patients cannot face with equanimity a long operation upon themselves even when pain is entirely absent, and they are liable as the result of fright alone to become faint and collapsed either during, or soon after, the operation. As most secondyear students and nurses know from personal experience, it is no slight ordeal to be present at a long operation, even

8 The Lancet, vol. i., 1902, p. 1098. when the subject is someone else. How much more difficult when the subject is oneself! As Dr. Crile has pointed out, a considerable degree of shock may occur from mental anxiety alone, and it is our duty to protect the patient from this as far as possible.

Dr. Fergusson is alarmed at the possibility of the patient's struggling during an abdominal operation, but this should never occur with gas and oxygen if a good anæsthetist is available, and I personally have had no experience of it. The method is, of course, still rather new to many anæsthetists, but I feel confident that great improvements in the production of analgesia with gas and oxygen will occur as the result of increased experience with the method. In America gas and oxygen as a general anæsthetic is being extensively used and is increasing in popularity, and I feel certain that the same will occur in this country, especially in London, where specialism in the administration of anæsthetics has reached its greatest development.

I am glad that Dr. Fergusson has drawn attention to the possible danger from chloroform and adrenalin in association. I have personally never seen any bad results from the combination, but this is probably because I have used only very dilute solutions of adrenalin and very small quantities of $\mathrm{CHCl}_{3}$. I believe, however, that Dr. Fergusson is correct and that $\mathrm{CHCl}_{3}$ should not be given when adrenalin is to be used, as there have been, to my knowledge, one or two deaths which might be attributed to this cause.

I am, Sir, yours faithfully,

London, July 26th, 1916. P. LOCK HART-M UMMERY, F.R.C.S.

\section{DIGITALIS IN AORTIC INCOMPETENCE. To the Editor of THE LANCET.}

SIR,-Dr. Seymour Taylor's article on the above subject in your issue of July 15th prompts me to record the following case of aortic regurgitation treated with tincture of digitalis.

A man, about 40 years old, was admitted to hospital on account of dyspncea and cedema of the legs. This condition was due to morbus cordis, and the presence of aortic regurgitation was evident by the usual signs. There was evidence of the disease being syphilitic. He was put to bed on a restricted diet. Some inconsiderable improvement followed. Digitalis was given with caution. Very definite improvement followed its use. This observation was controlled by a careful record of the daily output of urine. The following figures were obtained :-

$$
\begin{aligned}
& \text { Successive. Duration in Daily amount digitalis } \begin{array}{c}
\text { Daily average } \\
\text { excretion of }
\end{array} \\
& \begin{array}{l}
\text { periods. days. } \\
\text { given, in minims. }
\end{array}
\end{aligned}
$$

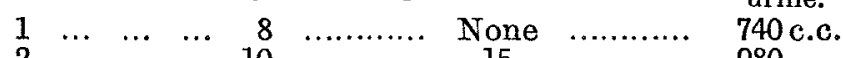

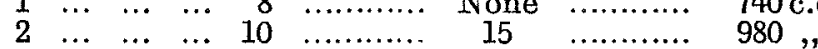

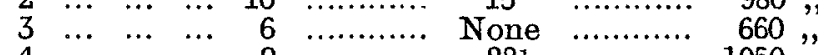

$$
\begin{aligned}
& \begin{array}{rrrrrrrrr}
4 & \ldots & \ldots & \ldots & 9 & \ldots \ldots \ldots & 22 \frac{1}{2} & \ldots \ldots \ldots \ldots & 1050, \\
5 & \ldots & \ldots & \ldots & 12 & \ldots \ldots \ldots \ldots & 22 \frac{1}{2} & \ldots \ldots \ldots \ldots & 1070
\end{array}
\end{aligned}
$$

The effect of the drug on the output of urine was apparent 48 hours after its first administration, and the above periods are taken accordingly.

This case illustrates one of the events which may follow the administration of digitalis and it is little more trouble to record than the pulse-rate. When the case presents definite clinical evidence, such as this, of the immediate value of digitalis in aortic incompetence one awaits comprehensive statistics, proving its effect in shortening life, before passing adverse judgment on its value.

I am, Sir, yours faithfully,

July 15th, 1916. GeofFrey Evans,

\section{MEDICAL ELECTRICITY DIRECT FROM THE MAIN.}

To the Editor of THE LANCET.

SIR,-In The LANCET of June 10th, p. 1176, a device is described for safely utilising the current from the main for medical purposes by interposing a water resistance. It claims to be something new, but is not water not only one of the best, but one of the oldest forms of resistance for galvanism? It has always been used by electrical engineers, and Professor Leduc -in whcse laboratories I first saw it-has always worked very largely with it. The experiments in his book (which was published many years ago and which is now the classic on ionic medication) were worked out entirely with "water resistances. Since the 